\title{
Identification of Subsurface Temperature Distribution of the Geothermal Manifestation Area in Lokop Indonesia
}

\author{
Fajriani $^{1,{ }^{*},}$ Dona Mustika ${ }^{2}$, Wan Alamsyah ${ }^{3}$, Rachmad Almi Putra ${ }^{1}$ \\ ${ }^{1}$ Department of Physics, ${ }^{2}$ Department of Physics Education, ${ }^{3}$ Department of Civil Engineering \\ University of Samudra \\ Langsa, Indonesia \\ *fajriani@unsam.ac.id
}

\begin{abstract}
Geophysical studies have been conducted to see the distribution of temperature below the surface of geothermal areas. Temperature spread measurements are performed using temperature sensors designed with microcontrollers so that data can be read and sent to servers with an Internet of Things (IoT) approach to users. In this study, 13 electrodes were developed with a length of $1 \mathrm{~m}$ and each electrode consisted of two sensors with intervals between sensors of $0.5 \mathrm{~m}$. The process of data collection is done by sounding and mapping, namely making a vertical array of temperature sensors, the next step is to place several electrodes scattered at the research site in a horizontal position, this aims to obtain horizontal temperature distribution. Based on the contour map of geothermal distribution below the surface, it was found that subsurface temperatures increased in the Northwest direction from the research site. The Northwest area of the research site is a hot spring so it can be indicated that the heat flow comes only from the springs.
\end{abstract}

\section{Keywords—sensor, temperature, geothermal, lokop}

\section{INTRODUCTION}

Geothermal energy is the heat energy contained in rocks and fluids are in it that is below the surface of the earth. Geothermal is a renewable and environmentally friendly natural resource. This resource is one of the alternative energy sources that must be developed to produce electricity and as an effort to increase the growth of electricity development in Indonesia. One of the region that has geothermal potential but has not been optimally developed as a reserve of geothermal energy sources by the government is Aceh. Of the 15 potential geothermal resource locations in Aceh, three have been developed in the Geothermal Working Area, namely Geureudong, Jaboi, and Seulawah Agam. However, other locations are still in the early stages of study, namely by determining areas that have geothermal manifestations [1].

The initial review determined the area of geothermal potential by looking at the presence of geothermal manifestations that appeared on the surface. Just like the Lokop
Village in East Aceh Regency which has geothermal potential is characterized by the presence of hot springs. However, there has been no further research in geophysical measurement. Therefore, a study is needed to maximize the potential of existing resources. Initial geophysical studies can be done by knowing the distribution of temperature below the surface of geothermal manifestation areas.

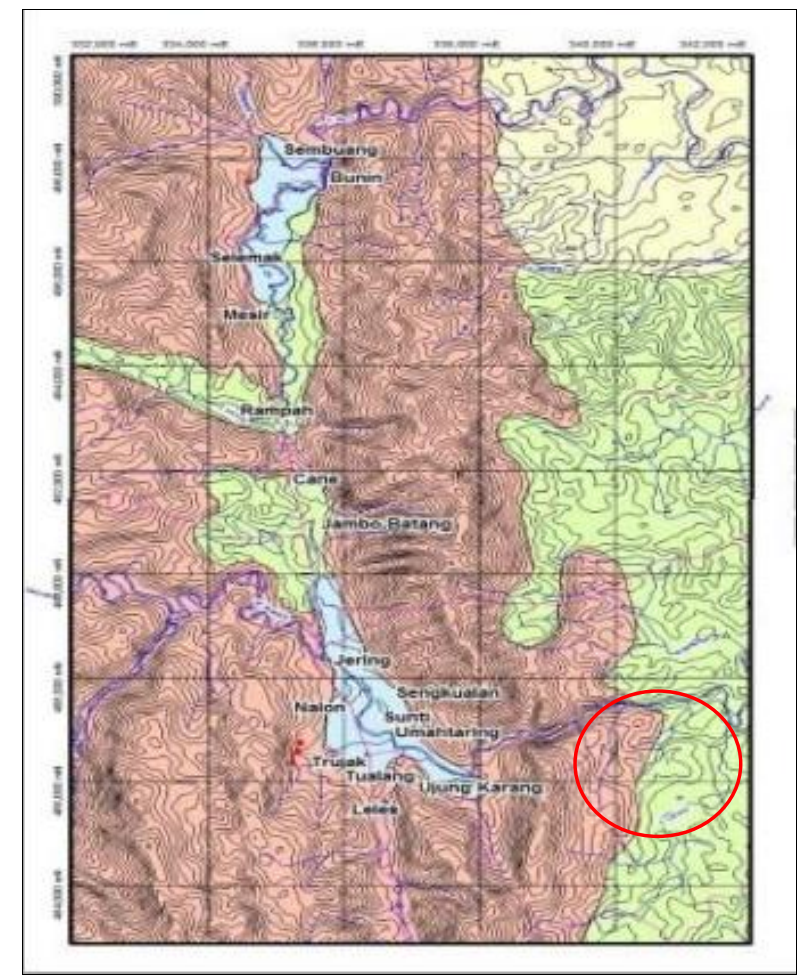

Fig. 1. Study area.

The research site is in the Lokop geothermal manifestation area. Research is only done around the hot spring area. Many studies regarding monitoring of subsurface temperature 
distribution have been developed using temperature sensors that are inserted into the subsurface [2,3].

In this research, the subsurface temperature distribution also uses a temperature sensor which is developed using the internet of things network in the process of collecting data that is read by the sensor during data acquisition.

\section{LITERATURE REVIEW}

In improving Indonesia's electricity development, the government through the Ministry of Energy and Mineral Resources has established areas throughout the island in Indonesia that have the prospect of the existence of geothermal resources. One of the early stages in determining geothermal potential area is by reviewing the presence of hot springs. After the manifestation of geothermal is seen on the surface, further research is carried out in the field of geosciences. Research in the field of geosciences includes geology, geophysics, and geochemistry. Geophysically, the first survey can be done by looking for information on the spread of subsurface temperatures in potential geothermal areas.

The temperature of rocks or soil near the Earth's surface is produced almost entirely from heating by the sun through radiation, evaporation, and various heat-absorbing processes. At certain surface locations the heat supplied from below the surface is relatively constant; it represents the heat of the interior locally equipped with heat from subsurface oxidation or other local heat sources and is responsible for the temperature of rocks below the zone where the surface temperature effect is visible. Temperatures at a certain depth in any area, however, depend not only on the flow of heat through the rocks but on the thermal properties of the rocks, and at surface temperatures with which sub-surface temperatures are in balance or that they adjust.

The main models of lower heat transfer to the surface are conduction and convection. In mapping regional heat flows, the important goal is to separate processes near the surface, such as groundwater flow and hydrothermal circulation, from deeper heat flows from Earth's interior. Knowledge of spatial variations in geothermal gradients and heat flows is of direct importance to the growing geothermal investigations around the world [4].

Temperatures increase along with depths on Earth, indicating that heat is generated at depth and transferred through layers of rock and sediment to the surface. The socalled terrestrial heat flow is explained by the following equation [5] :

$$
Q_{z}=\frac{\Delta T}{\lambda \Delta D}
$$

Where,

$Q_{z}=$ Heat flow per unit area in the vertical direction

$\lambda=$ Thermal conductivity

$\frac{\Delta T}{\Delta D}=$ Geothermal gradient
Basel et al use temperature distribution calculations for Turkey based on gradient values used to obtain sub-surface temperature maps for depths of $500 \mathrm{~m}$ and $1000 \mathrm{~m}$. Maps are built using Arc GIS software and geostatistic methods. Two data sets are used to obtain maps. Data Set 1: 420 data points obtained from wells with at least a depth of $1 \mathrm{~km}$ and Data Set 2: 555 data points obtained from relatively shallow 100/150 m wells. Variogram models using computational sub-surface temperature values are set, and then predictions are made using several geostatistical methods. Furthermore, maps are illustrated for regional bases and entire countries, and maps are compared to each other using different geostatistic techniques. All maps are created using the Geostatistical Analyst extension for ArcGIS ESRI software [6].

Wenas et al. collect subsurface heat distribution data with direct measurements. The measurement area is separated by the type of manifestation area and adjusted according to the physical state of the manifestation. For soil manifestations of steam, warm soil, and alteration rock, the measured data are surface temperature and subsurface temperature at depth 50 $\mathrm{cm}, 100 \mathrm{~cm}, 150 \mathrm{~cm}$, and $200 \mathrm{~cm}$, and also the manifestation area. Data processing using Excel and surfer applications. Once the data obtained from field measurements is obtained, the next step is analysis to obtain subsurface temperature distribution data and temperature gradients [7].

\section{Methodology}

Data of subsurface temperature distribution is carried out by determining the trajectory around geothermal manifestations. Data collection is done by sounding that arranges of temperature sensors designed vertically. Furthermore, mapping is carried out to obtain the distribution of temperature horizontally by placing some electrodes that have installed sensors at the measurement site horizontally forming a grid. In this study developed thirteen electrodes with a length of $1 \mathrm{~m}$ and each electrode composed of 2 sensors with a space between sensors $0.5 \mathrm{~m}$. Measurements will be taken for 2 hours to see the temperature change.

In this system, the software is needed to program microcontrollers that can read and transmit data that can be read by sensors to the server with an Internet of Things approach to the user.

The temperature data obtained in the field will be processed using Microsoft excel to see the temperature changes of each point in the period of the research conducted and then use software surfer to obtain a 2D cross-sectional contour map that displays the distribution of sub-surface temperature distribution in the research area.

\section{RESULTS}

The research data was taken at 13 research locations. From 13 points, data sent by IoT to the web can be read directly by the user. Temperature data were recorded for two hours from 2 to $4 \mathrm{p} . \mathrm{m}$. The temperature data recorded is then processed using Surfer software until contours are obtained as shown 
below. The following images are the contours of the temperature spread for some time.

- Measurement at $2.00 \mathrm{pm}$
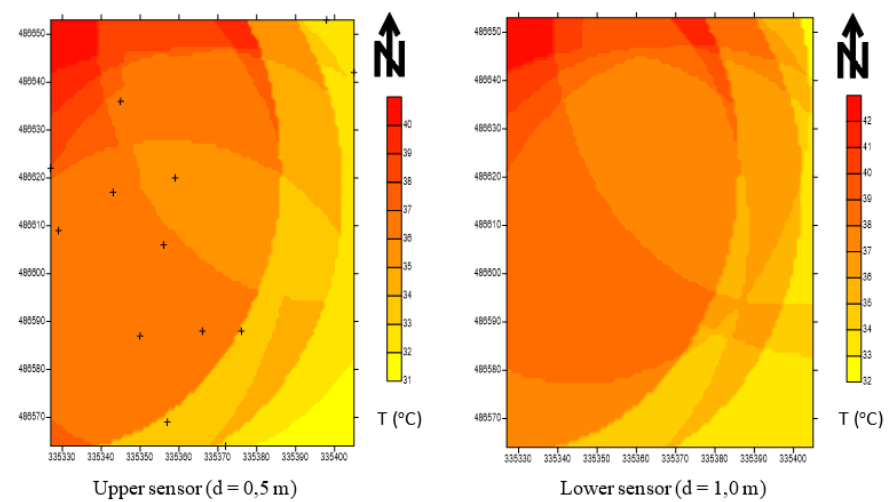

Fig. 2. Temperature Subsurface at $2.00 \mathrm{pm}$.

- Measurement at $2.30 \mathrm{pm}$
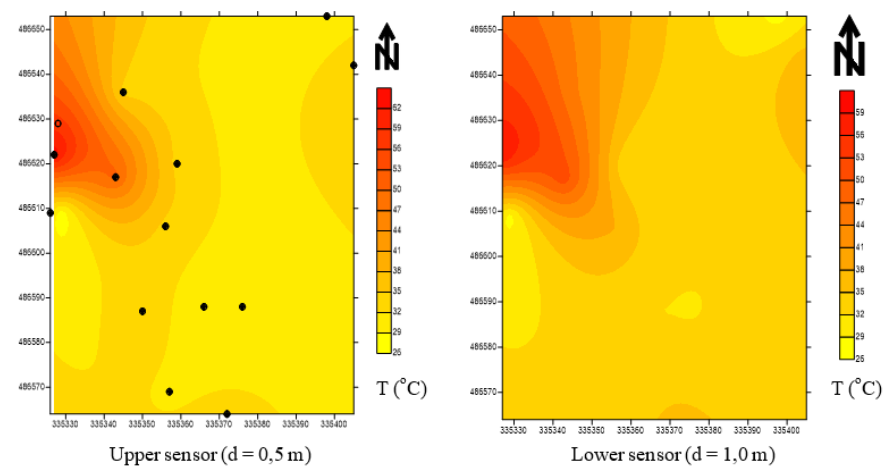

Fig. 3. Temperature Subsurface at $2.30 \mathrm{pm}$.

- Measurement at $3.00 \mathrm{pm}$
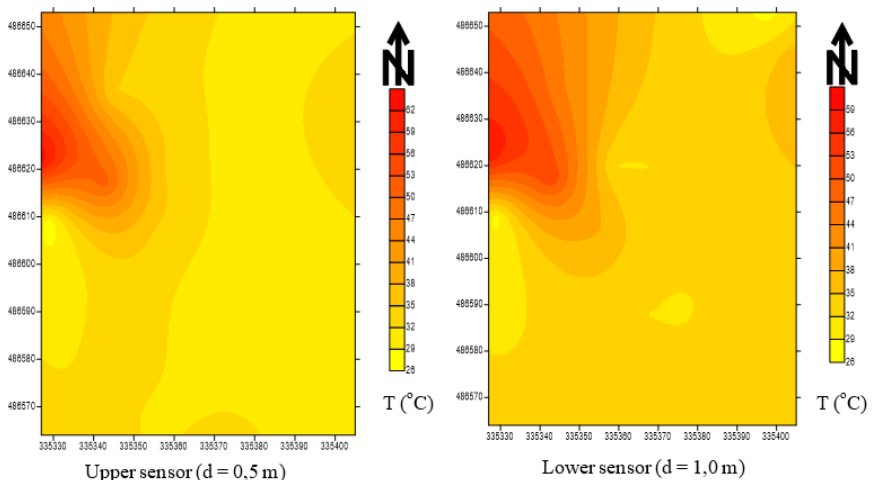

Fig. 4. Temperature Subsurface at $3.00 \mathrm{pm}$.
- Measurement at $3.30 \mathrm{pm}$
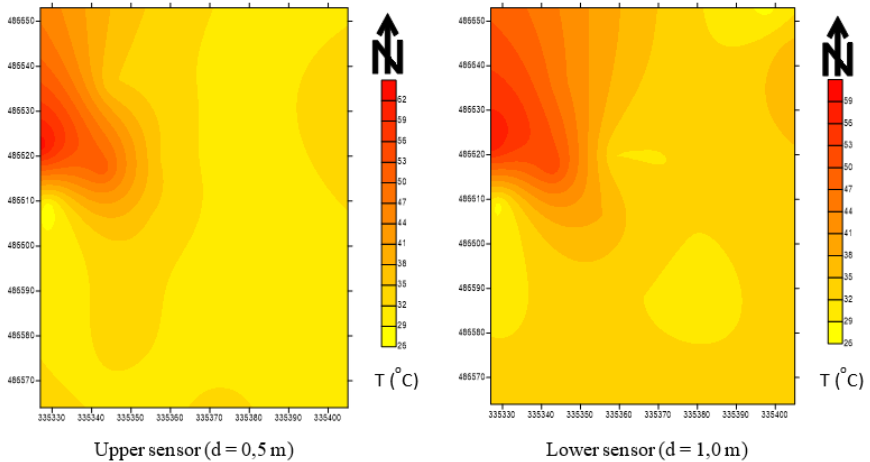

Fig. 5. Temperature Subsurface at $3.30 \mathrm{pm}$.

- Measurement at $3.45 \mathrm{pm}$
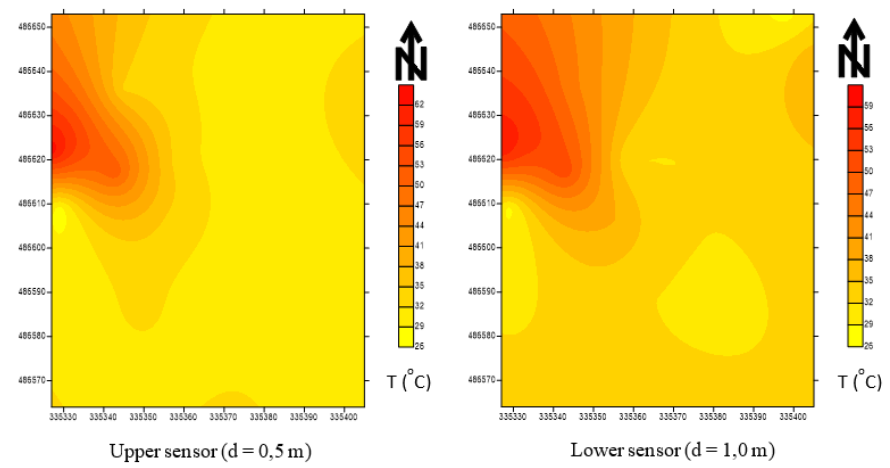

Fig. 6. Temperature Subsurface at $3.45 \mathrm{pm}$.

From the contour map shown above, the distribution of temperature in the geothermal manifestation area is increasing in subsurface temperatures $[8,9]$. The approximate location of geothermal reservoirs follows a measurable subsurface heat distribution. It is based on the existence of geothermal reservoir rocks and the relationship between the flow of hot water from water sources in reservoir rocks $[10,11]$. The heat is spreading in this area towards the Northwest. This directive follows the direction of sembuang, Jering, and sunti faults that lead to the Northwest-Southeast which is an association of the great mistakes of Sumatra. The potential location of geothermal research is the sweetness of the existence of faults. Thus it can be estimated that the location of the geothermal reservoir research site is located in the deep Northwest. It is also based on direct observations in the field where the hot spring is located at the Northwest point of the research site.

\section{CONCLUSION}

The spread of geothermal in the location of geothermal lokop, precisely trujak village district serbajadi east Aceh district, heading to the Northwest. Geothermal is the result of manifestations of faults, seen from the topographical appearance of research locations located in the faulty depression zone. 


\section{ACKNOWLEDGMENTS}

Thank you to LPPM-PM Samudra University who has funded this research through the grant of DIPA UNSAM research program in 2020 .

\section{REFERENCES}

[1] Direktorat Panas Bumi, Buku Panas Bumi. 2017.

[2] J.M.A. Márquez, M.Á.M. Bohórquez, and S.G. Melgar, "Ground thermal diffusivity calculation by direct soil temperature measurement. application to very low enthalpy geothermal energy systems," Sensors (Switzerland), vol. 16, no. 3, 2016, doi: 10.3390/s16030306.

[3] R.E. Zehner, K.N. Tullar, and E. Rutledge, "Effectiveness of 2-meter and Geoprobe shallow temperature surveys in early stage geothermal exploration," Trans. - Geotherm. Resour. Counc., vol. 36 2, pp. 825841, 2012.

[4] Á. Hjartarson, "Heat Flow in Iceland," in World Geothermal Congress 2015, 2015, no. April, pp. 1-4.

[5] J. Forrest, E. Marcucci, and P. Scott, Geothermal Gradients and Subsurface Temperatures in the Northern Gulf of Mexico, 2007,
[Online].

Available: https://www.researchgate.net/publication/228488170\%0AGeothermal.

[6] E. Didem Korkmaz Başel, A. Satman, and U. Serpen, "Predicted Subsurface Temperature Distribution Maps for Turkey," in Proceedings World Geothermal Congress, 2010, no. April, pp. 25-29.

[7] D.R. Wenas, D.A. Tulandi, and C.A.N. Bujung, "Geothermal gradient and subsurface temperature for estimation of sources, patterns and heat flow directions in the hydrothermal area of Minahasa Indonesia," J. Crit. Rev., vol. 7, no. 5, pp. 905-907, 2020.

[8] M.N. Ali, U. Harmoko, G. Yuliyanto, and T. Yulianto, "Model of Temperature Distribution Geothermal Pesanggrahan Geothermal System, Central Java, Indonesia,” Int. J. Recent Trends Eng. Res., vol. 4, no. 11, pp. 87-94, 2018.

[9] Y. Uchida et al., "Subsurface Temperature Survey in Thailand for Geothermal Heat Pump Application," Subsurf. Temp. Surv. Thail. Geotherm. Heat Pump Appl., vol. 33, no. 2, pp. 93-98, 2011.

[10] S.K. Garg, J.W. Pritchett, P.E. Wannamaker, and J. Combs, "Characterization of geothermal reservoirs with electrical surveys: Beowawe geothermal field," Geothermics, vol. 36, no. 6, pp. 487-517, 2007.

[11] C. Peng, B. Pan, L. Xue, and H. Liu, "Geophysical survey of geothermal energy potential in the Liaoji Belt, northeastern China," Geotherm. Energy, vol. 7, no. 1, 2019. 